\title{
Voltage Utilization Enhancement of Dual Inverters by Model Predictive Control for Motor Drive Applications
}

\author{
Zhen Huang, Tao Yang, Paolo Giangrande, Michael Galea, Cristian Garcia, Marco Rivera, Patrick Wheeler, José Rodríguez
}

\begin{abstract}
This paper proposes a model predictive control (MPC) method to improve the voltage utilization of dual inverters compared to utilizing previously addressed techniques. The enhancement can reach up to $10 \%$ and this benefit has been through simulations on an open-end winding induction motor.
\end{abstract}

\section{INTRODUCTION}

Dual converters are one of the most promising multilevel converters for motor drive applications [1]. This is mainly due to their fault-tolerance ability [2] and the possibility of generating high number of voltage levels [3]. This paper studies the dual converter with a floating capacitor (FC), as shown in Fig.1, since it is able to avoid the circulation of zero-sequence current and no need for any isolation circuitry, due to one floating bridge [4].

Regarding the dual converter with FC, one of research hotspots is investigating the suitable approach to enhance the voltage utilization of DC-link [4]-[7]. This is extremely critical for the motor drive applications [8]. Because the higher applicable voltage allows extending the constant torque region of the motor, the further starting of flux weakening operation could be postponed. In [6], it is reported that due to the limitation of multilevel output and the FC voltage regulation, the DC-link voltage is under-utilized. After that, an active space vector modulation (SVM) method that relies on the feedback of instantaneous phase current is addressed [4]. Particularly, this active modulation scheme can boost the voltage utilization of converters by at least $10 \%$.

Apart from using the SVM method, the model predictive control (MPC) technique has been received increasing attention. Compared to the SVM method, the benefits of MPC can be summarized as [5]:

1. Fast dynamic response;

2. The ability to include constraints and non-linearities;

3. Control of multiple variables, such as controlling 'load current' and 'DC-link voltage' for dual converters in a single control loop, without the need for complex calculation;

For instance, an MPC technique for dual converters is described in [5] and an enhanced technique with fixed switching frequency is proposed in [7]. However, the voltage utilization of DC-link by MPC has not been considered in the previous paper. More importantly, the appropriate assignment of weighting factor for dual converter topologies is not studied as well. In this paper, a technique based on MPC is addressed to enhance the voltage utilization of dual converter compared to using the active modulation proposed in [4].

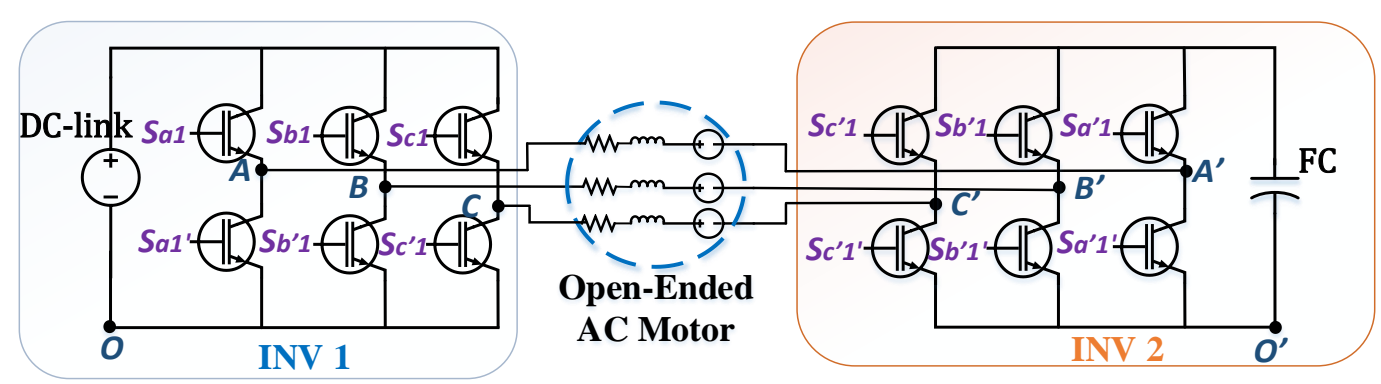

Fig.1. Schematic of the dual inverter. 


\section{Evaluation FunCtions}

Regarding the motor drive system of the dual inverter, there are two control objectives, which are the current and FC voltage. They are represented by two cost functions $g_{i}$ and $g_{v_{-}}$in (1) and (2), respectively. In particular, $k+$ 2 means two samples ahead. In (3), the overall evaluation function is written where the weighting factor $\lambda$ determines the outcomes of the function. Actually, the $\lambda$ is the importance allocation between $g_{i}$ and $g_{v_{-} f c}$.

Regarding the SVM method, the weighting factor $\lambda=0$ in (3) since the modulation is following the nearest three vector (NTV) principle. However, MPC technique applies the weighting factor, which can be also considered as the trade-off between harmonic distortions in the output current and FC voltage regulation.

$$
\begin{gathered}
g_{i}=\left|\left(i_{s d}^{* k+2}-i_{s d}^{k+2}\right)\right|+\left|\left(i_{s d}^{* k+2}-i_{s d}^{k+2}\right)\right| \\
g_{v_{-} f c}=\left|\left(V_{f c}^{*}-V_{f c}^{k+2}\right)\right| \\
g=g_{i}+\lambda * g_{v_{-} f c}
\end{gathered}
$$

\section{CONTROL SCHEME}

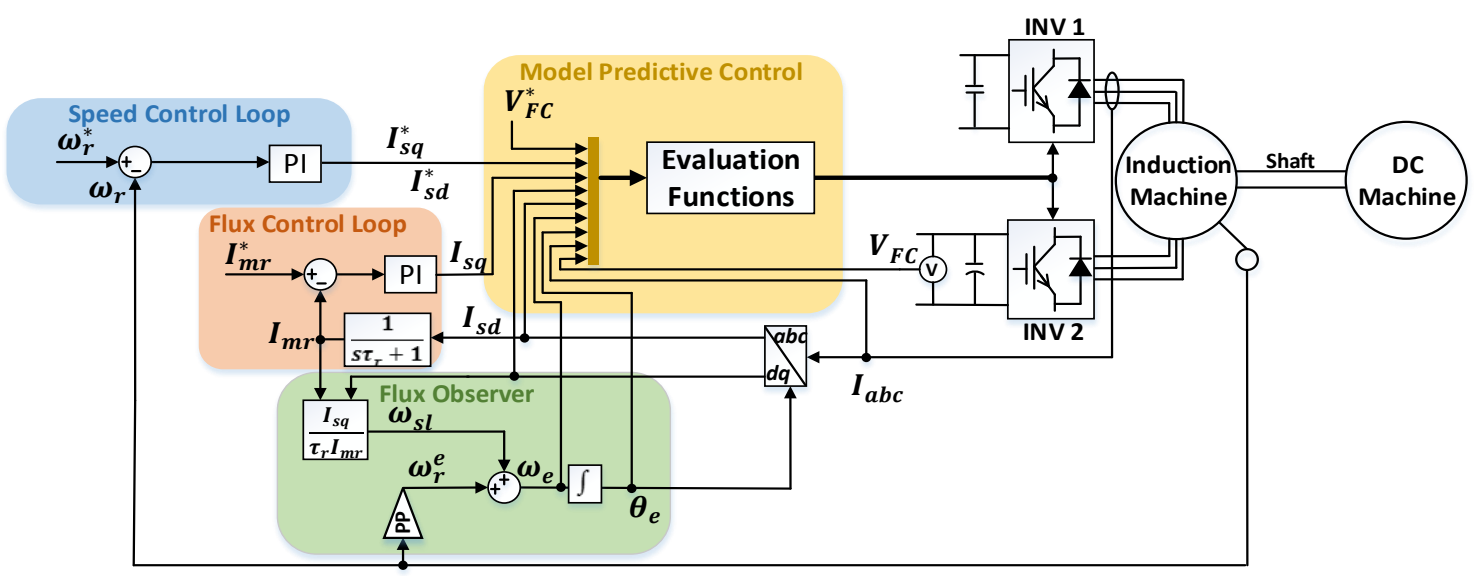

Fig.2. Schematic of MPC for the motor drive with dual inverter

Fig.2 depicts the MPC schematic on an open-end drive system. This system consists of the main inverter (INV 1) supplied by a DC-link, sub inverter (INV 2) supplied by an FC, and an open-end winding induction motor connected mechanically with a DC machine through a shaft. Regarding the MPC, it replaces the SVM modulator such that it takes the responsibilities of controlling current and voltage regulation of FC at the same time. As presented in Fig.2, the proposed MPC technique requires the information of reference FC voltage $V_{F C}^{*}$, reference qaxis stator current $i_{s q}^{*}$, reference $\mathrm{d}$-axis stator current $i_{s d}^{*}$, measured d-axis stator current $i_{s d}$ and measured q-axis stator current $i_{s q}$.

\section{Simulation Results}

\section{Table I. PARAMETERS OF MOTOR DRIVE}

\begin{tabular}{lc}
\hline DC-link Voltage of INV1 & $500 \mathrm{~V}$ \\
FC Voltage of INV2 & $250 \mathrm{~V}$ \\
Switching Frequency & $5 \mathrm{kHz}$ \\
Sample Frequency (MPC) & $20 \mathrm{kHz}$ \\
\hline
\end{tabular}


The test condition is to set the speed reference $\omega_{\text {ref }}=1150 \mathrm{rpm}$ at $0.021 \mathrm{~s}$ and apply the load torque $T=30.5 \mathrm{~N} *$ $m$ at 0.6s. Fig. 3 and Fig. 4 display the performance comparison by using SVM technique and MPC technique. From Fig.3, it demonstrates clearly the voltage of FC $V_{f c}$ by using SVM technique could not maintain the demand value and FC is discharged to zero. Meanwhile, the real speed could not follow the reference at $1150 \mathrm{rpm}$. However, under the same speed and same load condition, the voltage of FC $V_{f c}$ by using MPC technique is regulated around the demand value, as presented in Fig.4. These two figures prove that the MPC could allow dual converter providing higher voltage compared to using SVM technique. Fig.5 shows the maximum base speed comparison between SVM that is based on the nearest three vectors (NTV) and MPC technique for a certain load condition. It demonstrates that the base speed improvement, which is proportional to the voltage utilization, could be enhanced by up to $10 \%$.

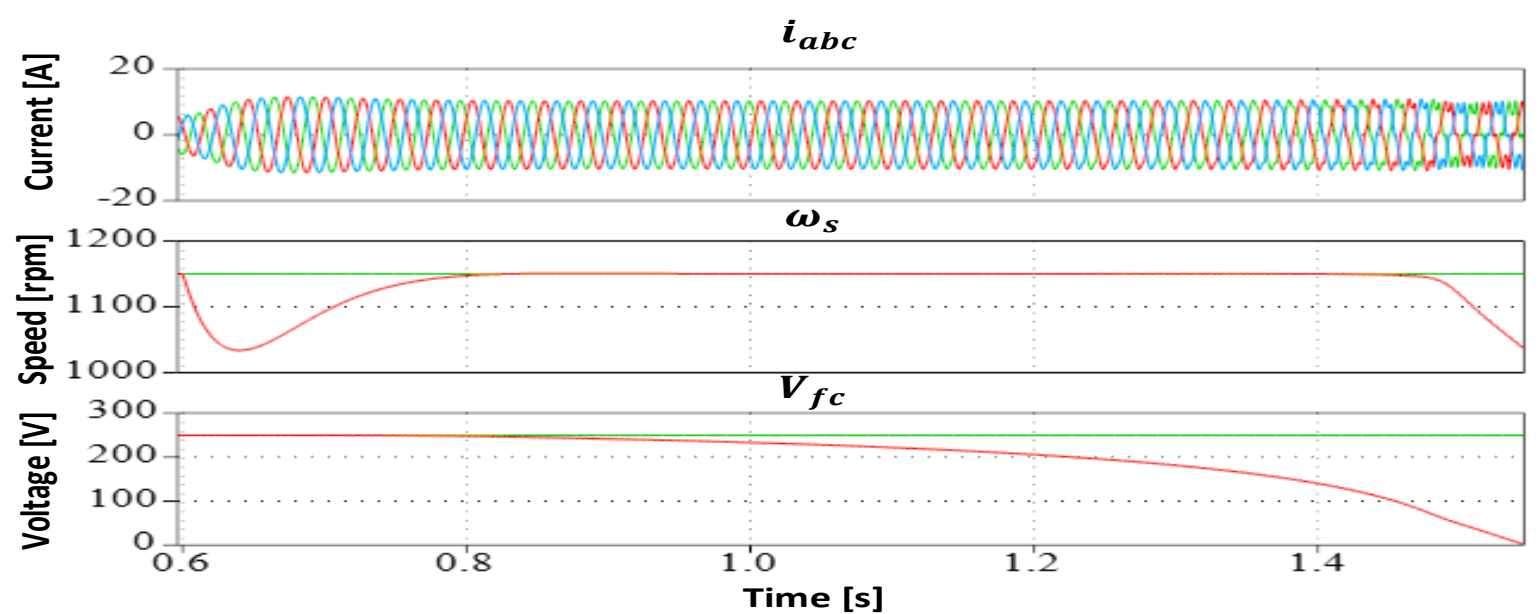

Fig.3. Performance of the motor drive by using SVM technique

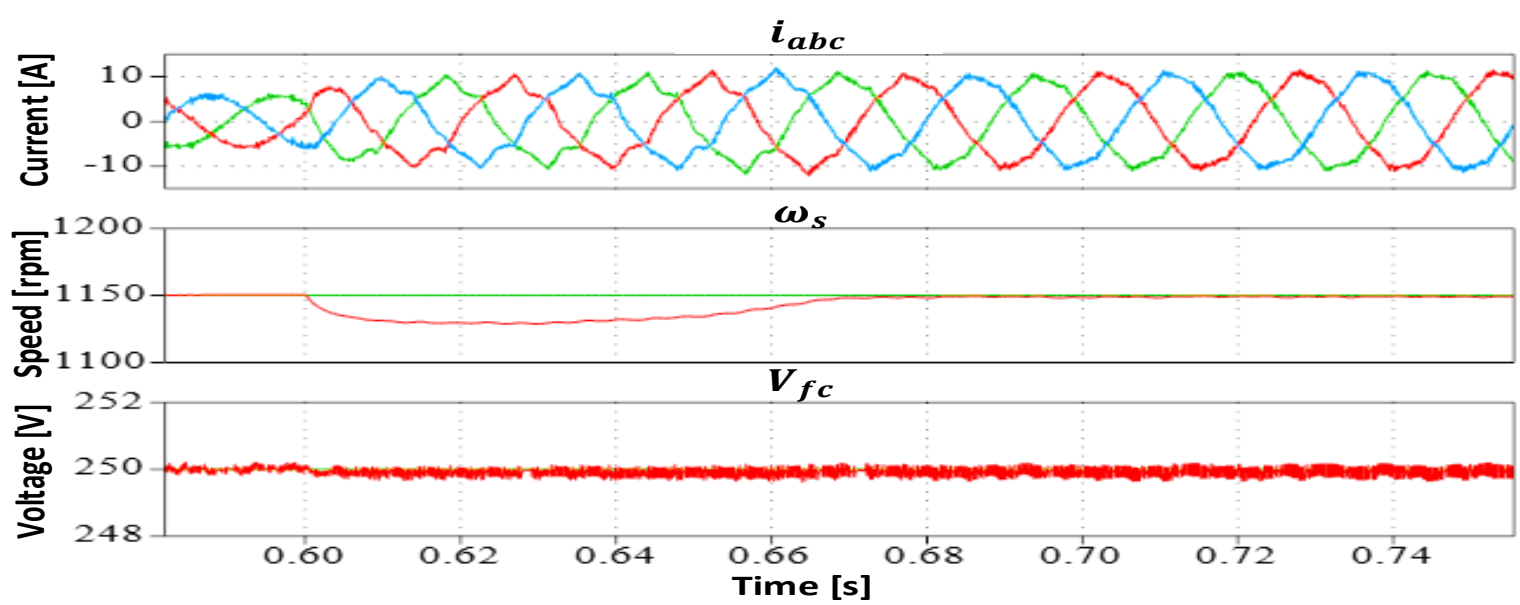

Fig.4. Performance of the motor drive by using MPC technique

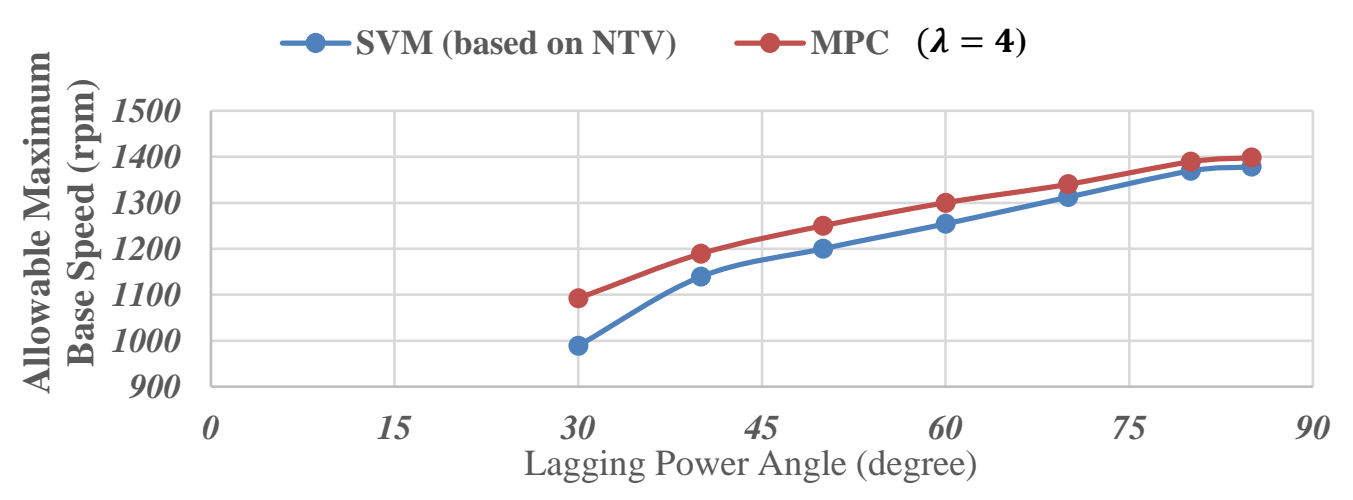

Fig.5. The improvement of base speed by using MPC technique 


\section{EXPERIMENTAL RESULTS}

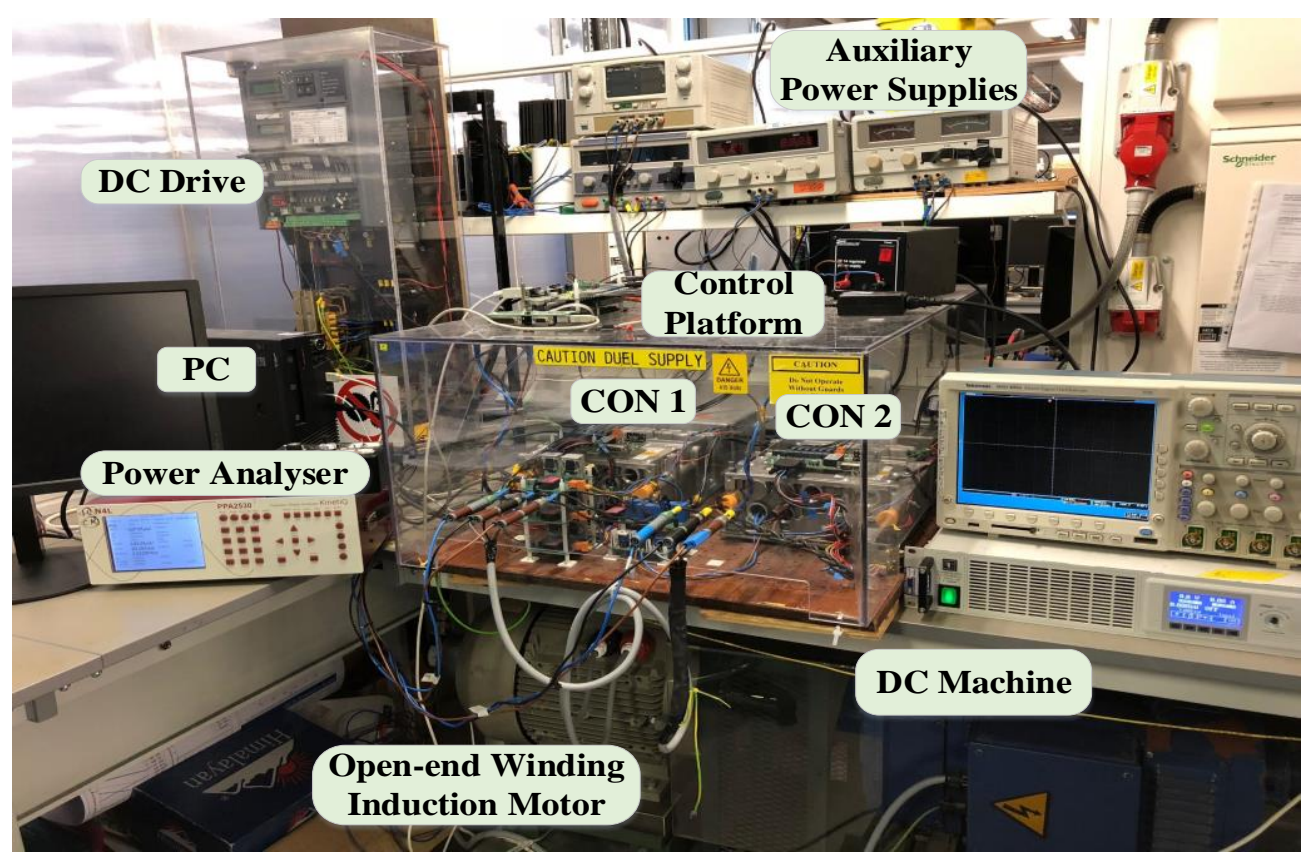

Fig.6. Experimental rig set-up

In Fig.6, the chosen power converters are commercial two-level converters produced by SEMIKRON. These converters have integrated gate drivers with DC-side capacitor of $1250 \mu \mathrm{F}$ capacitance, RC snubber, and inputoutput common mode choke. The control platform consists of a DSP and a FPGA board. The DC machine is connected mechanically to the open-end winding induction motor to act as a load. It is operated under torque control using an industrial DC drive, thus variable load torque on the induction motor is applicable.

\section{REFERENCES}

[1] S. Tewari and N. Mohan, "Matrix Converter Based Open-End Winding Drives With Common-Mode Elimination: Topologies, Analysis, and Comparison," IEEE Trans. Power Electron., vol. 33, no. 10, pp. 8578-8595, 2018.

[2] V. F. Pires, D. Foito, and J. F. Silva, "Fault-Tolerant Multilevel Topology Based on Three-Phase H-Bridge Inverters for Open-End Winding Induction Motor Drives," IEEE Trans. Energy Convers., vol. 32, no. 3, pp. 895-902, 2017.

[3] S. Lakhimsetty and V. T. Somasekhar, "Discontinuous decoupled SVPWM schemes for a four-level open-end winding induction motor drive with waveform symmetries," IET Power Electron., vol. 11, no. 2, pp. 280-292, 2018.

[4] Z. Huang, T. Yang, P. Wheeler, M. Galea, P. Giangrande, and S. Chowdhury, "An Active Modulation Scheme to Boost Voltage Utilisation of the Dual Converter with a Floating Bridge," IEEE Trans. Ind. Electron., vol. 0046, no. c, pp. 1-1, 2018.

[5] S. Chowdhury and P. Wheeler, "Model Predictive Control for a Dual Active Bridge Inverter with a Floating Bridge," IEEE Trans. Ind. Electron., vol. 63, no. 9, pp. 5558--5568, 2016.

[6] S. Chowdhury, P. Wheeler, and C. Gerada, "A Multi-Level Converter with a Floating Bridge for Open-Ended Winding Motor Drive Applications," IEEE Trans. Ind. Electron., vol. 63, no. 9, pp. 5366--5375, 2016.

[7] S. Chowdhury, P. Wheeler, Z. Huang, M. Rivera, and C. Gerada, "Fixed Switching Frequency Predictive Control of an Asymmetric Source Dual Inverter System with a Floating Bridge for Multilevel Operation," IET Power Electron., pp. 2-10, 2018.

[8] S. Zhu, T. Cox, C. Gerada, and C. Li, "Design Considerations of Fault-Tolerant Electro- mechanical Actuator Systems for More Electric Aircraft ( MEA )," in ECCE 2018 - IEEE Energy Conversion Congress and Exposition, Proceedings, 2018, pp. 4607-4613. 